\title{
Comunicação poética: São Paulo sob quatro olhares
}

Adilson Citelli*

Professor titular do Departamento de Comunicações e Artes da ECA/USP, onde ministra cursos de graduação e pós-graduação. Orienta dissertações e teses nas áreas de Comunicação e Linguagem, com ênfase nas subáreas Comunicação/Educação, Comunicação/Linguagem. É coeditor da revista Comunicação \& Educação, bem como pesquisador $1 C$ do CNPq ${ }^{* * *}$. E-mail: citelli@uol.com.br

Ao longo do século XX, saltando de uma cidade provinciana, com pouco mais de um milhão de habitantes, à metrópole atual, por volta da Semana de Arte Moderna de 1922, São Paulo parece encarnar a figura da metamorfose ambulante celebrada por Raul Seixas. Lugar de convivência das muitas diversidades, sinônimo de dinamismo econômico, cultural, carrega consigo as contradições que singularizam o capitalismo periférico e dependente. Esse cenário multifacetado, instigante, complexo, vem sendo motivo, fonte de inspiração, razão do trabalho, de inúmeros romancistas, poetas, músicos, que elegeram (e muitos foram eleitos) São Paulo como elemento temático e de representação das suas produções e realizações artísticas.

Neste número, a revista Comunicação $\mathcal{E}$ Educação faz uma homenagem a São Paulo, apresentando alguns artistas que transformaram a cidade em ambiente para a elaboração de poemas e canções: Mário de Andrade, Paulo Vanzolini, Caetano Veloso e Tom Zé.

\section{MÁRIO DE ANDRADE}

Mário Raul de Moraes Andrade nasceu na cidade de São Paulo no dia 9 de fevereiro de 1893. Além de poeta, romancista e crítico de arte, destacou-se como um grande pesquisador das tradições populares brasileiras, sendo um dos principais responsáveis pela Semana de Arte Moderna de 1922. Nesse mesmo ano, publica o livro Pauliceia desvairada, obra que causou impacto nos meios literários da época. Mário de Andrade faleceu em 1945, na sua queridíssima São Paulo.

Após a sua morte foi publicado o livro de poesias Lira paulistana, mais uma obra dedicada a São Paulo na qual são abordados os contrastes sociais que já eram evidentes à época. O poema "Lira paulistana", que deu nome à obra, no entanto, descreve a íntima relação desenvolvida com diferentes locais da cidade. Segundo Piraceli, trata-se um poema-testamento, em que o autor deixa como herança e legado o seu próprio corpo:

* Com a colaboração de Cristine Vargas (revista Comunicação \& Educação - ECA/USP e FFLCH/USP).

** É autor de inúmeros artigos e livros, dentre os quais se destacam: Linguagem e persuasão (Ática: 1994); Comunicação e educação: a linguagem em movimento (Senac: 2000); Palavras, meios de comunicação e educação (Cortez: 2006). 
comunicação \& educação • Ano XV • número 3 • set/dez 2010

[...] deixou seu testamento: o próprio corpo-poema para ser lembrado na espacialidade urbana. Do pico do Jaraguá ao pátio do Colégio, passando pelos lugares em que viveu, o bardo se esquarteja de maneira literal mapeando a cidade, fecundando-a com seus órgãos sensoriais, transformando-os em monumentos em meio à topografia e às construções da memória ${ }^{1}$.

Através do corpo-poema, o poeta funde-se com a cidade, não existe mais poesia e poeta, ambos se transformam em uma única e mesma coisa. De forma corporal, Mário de Andrade substancializa sua relação com a cidade.

\section{Lira paulistana}

Quando eu morrer quero ficar, Não contem aos meus inimigos, Sepultado em minha cidade, Saudade.

Meus pés enterrem na rua Aurora, No Paissandu deixem meu sexo, $\mathrm{Na}$ Lopes Chaves a cabeça Esqueçam.

No Pátio do Colégio afundem O meu coração paulistano:

Um coração vivo e um defunto Bem juntos.

Escondam no Correio o ouvido Direito, o esquerdo nos Telégrafos, Quero saber da vida alheia, Sereia.

\section{PAULO VANZOLINI}

Paulo Emílio Vanzolini nasceu em 25 de abril de 1924, em São Paulo. Juntamente com Adoniran Barbosa é reconhecido como o grande nome do samba paulista. Movido pelo interesse em zoologia de vertebrados, entrou para a Faculdade de Medicina da Universidade de São Paulo, época em que passou a frequentar rodas boêmias e a compor seus primeiros sambas. Na década de 1950, trabalhou na TV Record na produção de programas musicais. Ingressou como pesquisador no Museu de Zoologia da Universidade de São Paulo, onde organizou uma das maiores coleções de répteis do mundo e exerceu o cargo de diretor. É um dos idealizadores da Fundação de Amparo à Pesquisa do Estado de São Paulo (Fapesp) e ativo colaborador do Museu de Zoologia da Universidade de São Paulo.

Em 1945, compôs seu maior sucesso, o samba-canção Ronda, que seria gravado pela primeira vez, em 1953, pela cantora Inezita Barroso. A canção tem como cenário a cidade de São Paulo, destacando o chamamento para aquela
O nariz guardem nos rosais, A língua no alto do Ipiranga Para cantar a liberdade.

Os olhos lá no Jaraguá Assistirão ao que há de vir, O joelho na Universidade, Saudade...

As mãos atirem por aí, Que desvivam como viveram, As tripas atirem pro Diabo, Que o espírito será de Deus. Adeus.
1. TIRAPELI, Percival. São Paulo: artes e etnias. São Paulo: Editora Unesp, 2007. p. 353 


\section{Comunicação poética • Adilson Citelli}

que era a sua mais famosa avenida, a São João. Trata-se de um texto marcado pelo desengano amoroso, pela busca incessante de uma mulher que procura encontrar o seu homem, o boêmio frequentador de bares e outras mulheres. $\mathrm{O}$ aceno com a possivel tragédia final lembra a estratégia que passou a ser bastante utilizada pelos jornais sensacionalistas para estampar notícias de crimes.

\section{Ronda}

De noite eu rondo a cidade

A te procurar sem encontrar

No meio de olhares espio em todos os bares

Você não está

Volto pra casa abatida

Desencantada da vida

O sonho alegria me dá

Nele você está

$\mathrm{Ah}$, se eu tivesse quem bem me quisesse

Esse alguém me diria

Desiste, esta busca é inútil

Eu não desistia

Porém, com perfeita paciência

Volto a te buscar

Hei de encontrar

Bebendo com outras mulheres

Rolando um dadinho

Jogando bilhar

E neste dia então

Vai dar na primeira edição

Cena de sangue num bar

Da avenida São João.

\section{CAETANO VELOSO}

Caetano Emanuel Vianna Telles Velloso nasceu em 7 de agosto de 1942, na cidade de Santo Amaro da Purificação, BA. Nos anos 1960, trabalhou em espetáculos e shows com Gilberto Gil, Tom Zé e Gal Costa, liderando o movimento Tropicalista. Em 1969, depois de ser preso pela ditadura militar, partiu para o exílio político na Inglaterra, onde permaneceu até 1972. Em 1986, comandou, ao lado de Chico Buarque, o programa de televisão Chico Eै Caetano. Em 1997, lançou seu primeiro livro, Verdade tropical. Em 2000, seu disco Livro, de 1998, ganhou o prêmio Grammy na categoria World Music.

Em 1978 Caetano Veloso gravou a canção Sampa. Embora seu lançamento tenha ocorrido quase dez anos após o fim do Tropicalismo, a canção conserva marcas temáticas e estilísticas do movimento. Sampa poetiza uma cidade de contrastes: a modernização socioeconômica acelerada e excludente, a vitalidade 
cultural, a convivência da diversidade. São Paulo é vista sob o olhar do migrante e sua tomada de consciência ante a metrópole carregada de vitalidade e contradições. Conquanto estampando uma primeira impressão negativa da cidade, algo incompreensível ("porque és o avesso do avesso do avesso do avesso"), ao final da canção, o eu poético incorpora o espaço, passando a fazer parte dele, podendo entendê-lo, admirá-lo, aceitá-lo ("E os novos baianos passeiam na tua garoa/E novos baianos te podem curtir numa boa").

\section{Sampa}

Alguma coisa acontece no meu coração Que só quando cruza a Ipiranga e a avenida São João É que quando eu cheguei por aqui eu nada entendi Da dura poesia concreta de tuas esquinas Da deselegância discreta de tuas meninas

Ainda não havia para mim Rita Lee

A tua mais completa tradução

Alguma coisa acontece no meu coração

Que só quando cruza a Ipiranga e a avenida São João

Quando eu te encarei frente a frente não vi o meu rosto

Chamei de mau gosto o que vi, de mau gosto, mau gosto

É que Narciso acha feio o que não é espelho

E à mente apavora o que ainda não é mesmo velho

Nada do que não era antes quando não somos mutantes

E foste um difícil começo

Afasto o que não conheço

E quem vende outro sonho feliz de cidade

Aprende depressa a chamar-te de realidade

Porque és o avesso do avesso do avesso do avesso

Do povo oprimido nas filas, nas vilas, favelas

Da força da grana que ergue e destrói coisas belas

Da feia fumaça que sobe, apagando as estrelas

Eu vejo surgir teus poetas de campos, espaços

Tuas oficinas de florestas, teus deuses da chuva

Pan-Américas de Áfricas utópicas, túmulo do samba

Mais possível novo quilombo de Zumbi

E os novos baianos passeiam na tua garoa

E novos baianos te podem curtir numa boa.

\section{TOM ZÉ}

Antônio José Santana Martins nasceu em 11 de outubro de 1936, na cidade de Irará, BA. O cantor, compositor e arranjador é considerado uma das 


\section{Comunicação poética - Adilson Citelli}

figuras mais originais da música popular brasileira. Participou, em 1968, da gravação do álbum Tropicália ou Panis et Circensis, obra definidora do movimento Tropicalista. A partir da década de 1990, ganhou notoriedade internacional, com o disco The Best of Tom Zé, que foi aclamado pela crítica, ficando entre os dez melhores da década em todo o mundo, na avaliação da revista Rolling Stone. Com o lançamento de seu CD Com Defeito de Fabricação, em 1999, Tom Zé retornou ao cenário da música brasileira.

Em 1968, no IV Festival de MPB da TV Record, Tom Zé ganhou o primeiro lugar com uma marchinha que homenageava e criticava a cidade ao mesmo tempo: São, São Paulo. A letra da canção foi construída em cima de antíteses figuradas pela cidade: multidão/solidão, moralismo/libertinagem, provincianismo/modernidade, amor/ódio. Caleidoscópio que bem representava - e de certo modo ainda representa - as tensões internas de uma cidade marcada pelos encontros do velho e do novo, em um momento do processo de industrialização e internacionalização que reconfigurava costumes, tradições, culturas, perspectivas políticas, lutas sociais. Segundo Perrone, Tom Zé vê São Paulo a partir de uma perspectiva paradoxal, marcada por uma mistura de estranhamento, aversão e fascinação ${ }^{2}$.

\section{São, São Paulo}

São, São Paulo quanta dor São, São Paulo meu amor

São oito milhões de habitantes De todo canto em ação Que se agridem cortesmente Morrendo a todo vapor E amando com todo ódio Se odeiam com todo amor São oito milhões de habitantes Aglomerada solidão Por mil chaminés e carros Caseados à prestação Porém com todo defeito Te carrego no meu peito

São, São Paulo quanta dor São, São Paulo meu amor

Salvai-nos por caridade Pecadoras invadiram Todo centro da cidade Armadas de rouge e batom Dando vivas ao bom humor Num atentado contra o pudor
A família protegida Um palavrão reprimido Um pregador que condena Uma bomba por quinzena Porém com todo defeito Te carrego no meu peito

São, São Paulo quanta dor São, São Paulo meu amor

Santo Antônio foi demitido Dos Ministros de cupido Armados da eletrônica Casam pela TV

Crescem flores de concreto Céu aberto ninguém vê Em Brasília é veraneio No Rio é banho de mar O país todo de férias Aqui é só trabalhar Porém com todo defeito Te carrego no meu peito

São, São Paulo quanta dor São, São Paulo meu amor.
2. PERRONE, Charles. Performing São Paulo: vanguard representations of a Brazilian Cosmópolis (Artes de São Paulo: re presentações de vanguarda de uma cosmópole brasileira). Latin American Music Review, v. 23 , n. 1 (2002), 60-78. Apud NAPOLITANO, Marcos. O olhar tropicalista sobre a cidade de São Paulo. Várias histórias [on-line]. 2005 , v. 21, n. 34 , pp. 504-520. Disponível em: <http://www.scielo.br/ scielo.php?script $=$ sci_ arttext\&pid=S0104 $-87752005000200014 \&$ In $\mathrm{g}=\mathrm{en} \& \mathrm{nrm}=\mathrm{iso}>$. Acesso em: 30 jun. 2010. 
comunicação \& educação • Ano XV • número 3 • set/dez 2010

\section{REFERÊNCIA BIBLIOGRÁFICA}

TIRAPELI, Percival. São Paulo: artes e etnias. São Paulo: Editora Unesp, 2007.

\section{Endereços eletrônicos}

VELOSO, Caetano. Biografia. Disponível em: <http://www.caetanoveloso.com. br/sec_biografia.php?language=pt_BR $>$.

ANDRADE, Mário de. Disponível em: $<$ http://www.releituras.com/marioandrade_ bio.asp. Acesso em: 30 jun. 2010>.

NAPOLITANO, Marcos. O olhar tropicalista sobre a cidade de São Paulo. Várias histórias [on-line], 2005, v. 21, n. 34, pp. 504-520. Disponível em: <http://www. scielo.br/scielo.php?script=sci_arttext\&pid=S0104-87752005000200014\&lng=en $\&$ nrm=iso>. Acesso em: 30 jun. 2010.

TOM ZÉ. Disponível em: <http://cliquemusic.uol.com.br/artistas/ver/tom-ze>. Acesso em: 30 jun. 2010.

VANZOLINI, Paulo. Disponível em: <http://www.dicionariompb.com.br/paulovanzolini/biografia $>$. Acesso em: 30 jun. 2010. 